\title{
Improved Single-Stage AC-DC LED-Drive Flyback Converter using the Transformer-Coupled Lossless Snubber
}

\author{
Gang-Youl Jeong ${ }^{\dagger}$ and Su-Han Kwon*
}

\begin{abstract}
This paper presents an improved single-stage ac-dc LED-drive flyback converter using the transformer-coupled lossless (TCL) snubber. The proposed converter is derived from the integration of a full-bridge diode rectifier and a conventional flyback converter with a simple TCL snubber. The TCL snubber circuit is composed of only two diodes, a capacitor, and a transformer-coupled auxiliary winding. The TCL snubber limits the surge voltage of the switch and regenerates the energy stored in the leakage inductance of the transformer. Also, the switch of the proposed converter is turned on at a minimum voltage using a formed resonant circuit. Thus, the proposed converter achieves high efficiency. The proposed converter utilizes only one general power factor correction (PFC) control IC as its controller and performs both PFC and output power regulation, simultaneously. Therefore, the proposed converter provides a simple structure and an economic implementation and achieves a high power factor without the need for any separate PFC circuit. In this paper, the operational principle of the proposed converter is explained in detail and the design guideline of the proposed converter is briefly shown. Experimental results for a $40-\mathrm{W}$ prototype are shown to validate the performance of the proposed converter.
\end{abstract}

Keywords: Single-stage, AC-DC Flyback converter, Transformer-coupled lossless (TCL) snubber, LED-drive

\section{Introduction}

Light emitting diodes (LEDs) have many advantages such as high lighting efficacy, environmental friendliness, long lifetime, and low maintenance requirement compared with conventional lighting sources such as incandescent or fluorescent lamps. Therefore, LEDs have become a good solution as a new lighting resource and are becoming increasingly more popular in offline lighting applications [1-5]. However, the LED drive circuit is an ac-dc converter. The ac-dc converter is usually composed of a full-bridge diode rectifier, a dc-link capacitor, and a switch-mode power supply (SMPS). The SMPS is a high frequency dcdc converter. The ac-dc converter is powered from the ac line voltage, only when the dc-link voltage is discharged and is lower than the rectified line voltage. Therefore, the input current of such a converter is highly distorted, which results in a large amount of harmonics and a low power factor. To address these problems, various power factor correction (PFC) ac-dc converters have been proposed and developed [6-8].

The PFC ac-dc converter has either a two-stage or singlestage structure. The two-stage ac-dc converter consists of two power-process stages with their respective control circuits, which are the PFC circuit and the high frequency

$\dagger$ Corresponding Author: Dept. of Electronic Information Engineering,

Soonchunhyang University, Korea. (gangyoul@sch.ac.kr)

* Dept. of Electronic Information Engineering, Soonchunhyang

University, Korea. (1236shk@naver.com)

Received: June 24, 2015; Accepted: November 29, 2015 dc-dc converter $[9,10]$. Therefore the two-stage ac-dc converter increases the power losses and the manufacturing cost, and eventually its system efficiency and price competitiveness are reduced. In order to reduce the overall size and cost of the two-stage ac-dc converter, a number of single-stage ac-dc converters have been proposed and developed [11-13]. The main concept of the single-stage ac-dc converter is that the PFC circuit and the high frequency dc-dc converter are simplified by sharing the switches of the PFC circuit and the dc-dc converter to eliminate the switch and control circuit for the PFC circuit. These single-stage ac-dc converters have the advantages of being simple and cost-effective [10, 14-15]. However, the conventional single-stage ac-dc converters still have drawbacks since they require a high capacity dc-link electrolytic capacitor and a boost inductor for the PFC circuit, similar to the two-stage ac-dc converters, and have high voltage stress and high switching loss of the main switch.

Therefore, to overcome the drawbacks of the conventional single-stage ac-dc converter, the improved single-stage acdc LED-drive flyback converter using the transformercoupled lossless (TCL) snubber is proposed in this paper. The proposed converter has a simple structure composed of only a full-bridge diode rectifier and a conventional flyback converter with the TCL snubber. The TCL snubber circuit comprises only two diodes, a capacitor, and a transformercoupled auxiliary winding. Therefore, implementation of the proposed converter is easy and cost-effective. The TCL 
snubber limits the maximum voltage of the switch and recycles the energy stored in the leakage inductance of the transformer. Also, the switch voltage of the proposed converter is reduced at turn-on using a formed resonant circuit. The proposed converter thus achieves high efficiency. The proposed converter utilizes only one general PFC control IC as its controller and performs both the PFC (without any separate PFC circuit) and the output power regulation (using the critical conduction mode (CRM) control), simultaneously. However, the proposed converter achieves a high power factor. In this paper, the operational principle of the proposed converter is described in detail and the design guideline of the proposed converter is briefly presented. It is shown that the proposed converter performs well as a single-stage ac-dc converter for LEDdriving through experimental results for a $40-\mathrm{W}$ prototype.

\section{Operational Principle of the Proposed Converter}

Fig. 1 shows the circuit diagram of the proposed singlestage ac-dc LED-drive flyback converter using the TCL snubber. The proposed converter uses a full-bridge diode rectifier as its input stage without the dc-link electrolytic capacitor and the boost inductor. It also uses a conventional flyback converter, to which only the TCL snubber circuit is applied. The input voltage of the flyback converter is the full-wave rectified dc voltage from the commercial ac line voltage. As shown in Fig. 1, the TCL snubber circuit of the proposed converter consists of only two diodes, $D_{1}$ and $D_{2}$, a snubber capacitor $C_{n}$, and the transformer-coupled auxiliary winding $N_{a}$. The turn ratios of the transformer are $n_{s}=N_{s} / N_{p}$ and $n_{a}=N_{a} / N_{p}$, where $N_{p}$ is the primary turn number, $N_{s}$ is the secondary turn number, and $N_{a}$ is the auxiliary winding turn number.

Fig. 2 shows the theoretical waveforms in the steady state of the proposed ac-dc converter, and Fig. 3 shows the equivalent circuits of each mode of the proposed converter. As shown in Figs. 2 and 3, each switching period can be subdivided into five modes.

In order to illustrate the steady state operation of the

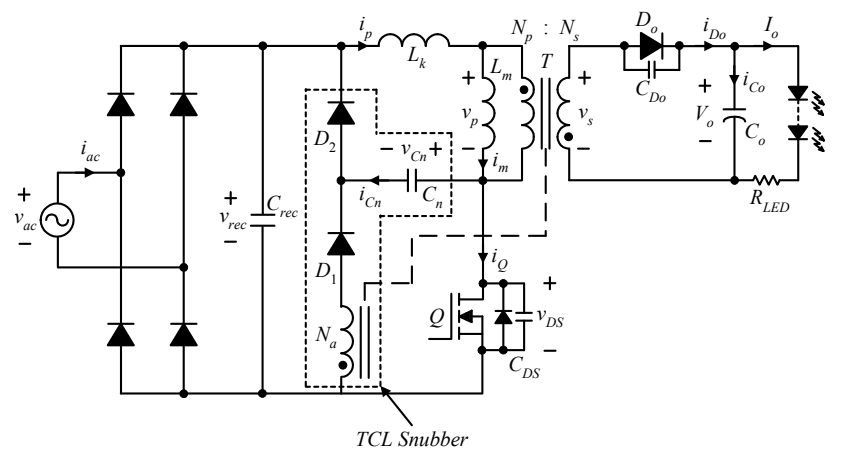

Fig. 1. Circuit diagram of the proposed single-stage ac-dc LED-drive flyback converter.

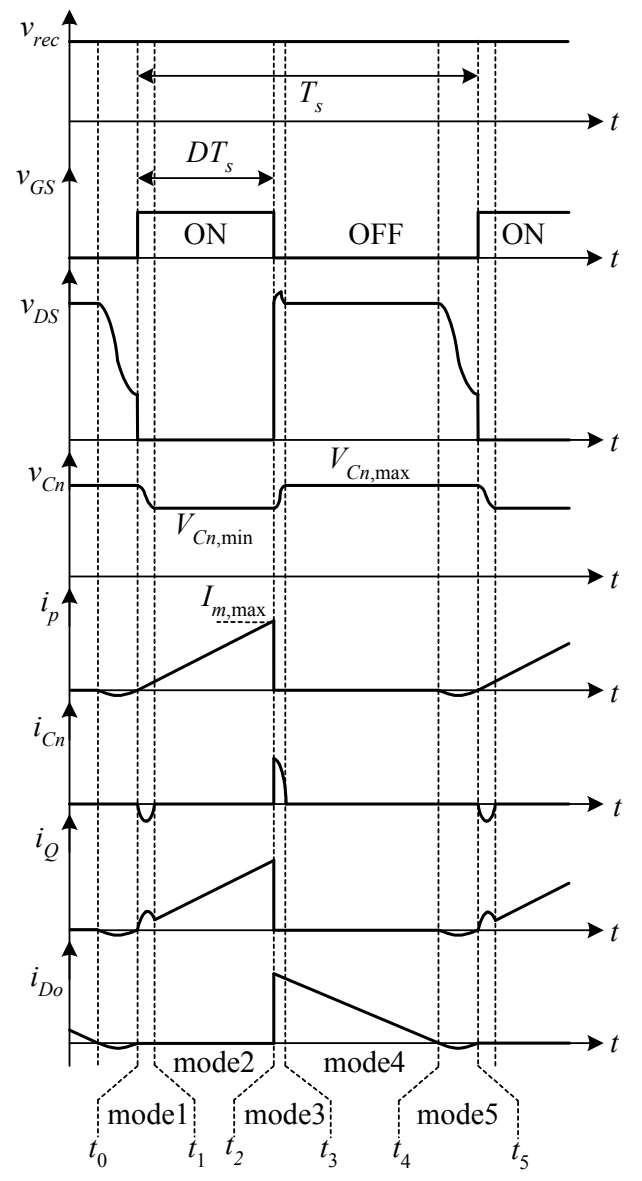

Fig. 2. Theoretical waveforms in the steady state of the proposed ac-dc converter.

proposed converter, the following assumptions are made.

1) Each semiconductor switch is ideal except for its parasitic capacitance, and the output filter capacitance $C_{o}$ is sufficiently large for its voltage ripple to be negligible.

2) The transformer $T$ is modeled as the magnetizing inductance $L_{m}$, the primary leakage inductance $L_{k}$, and an ideal transformer with turn ratios $n_{s}$ and $n_{a}$.

3) The magnetizing inductance $L_{m}$ is very large and is much greater than the primary leakage inductance $L_{k}$ $\left(L_{m} \gg L_{k}\right)$.

4) The rectified dc input voltage $v_{\text {rec }}$ is assumed to be constant during the switching period because the switching frequency is much faster than the ac line frequency.

Before mode 1 starts at time $t=t_{0}$, the switch current $i_{Q}$ is zero and the snubber capacitor voltage $v_{C n}$ is at a maximum.

Mode $1\left(t_{0} \sim t_{1}\right)$ : This mode starts when the MOSFET switch $Q$ is turned on at time $t=t_{0}$. The rectified dc input voltage $v_{\text {rec }}$ is then applied on the primary series inductance $L_{m}+L_{k}$ of the transformer, and thus the primary current $i_{p}$ charges the primary series inductance. At this time, the snubber diode $D_{1}$ turns on and the energy stored in the 


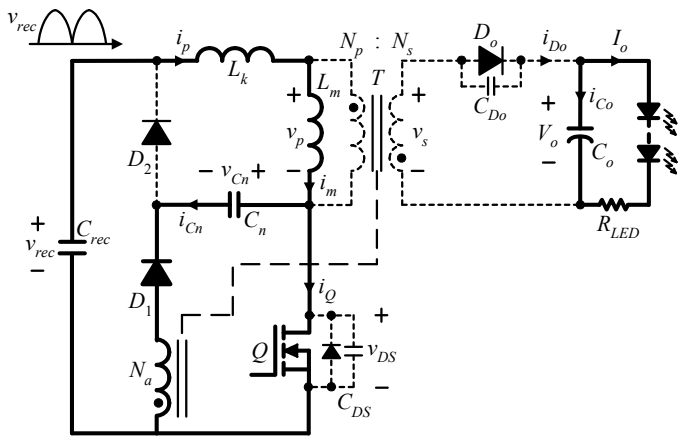

(a) Mode 1

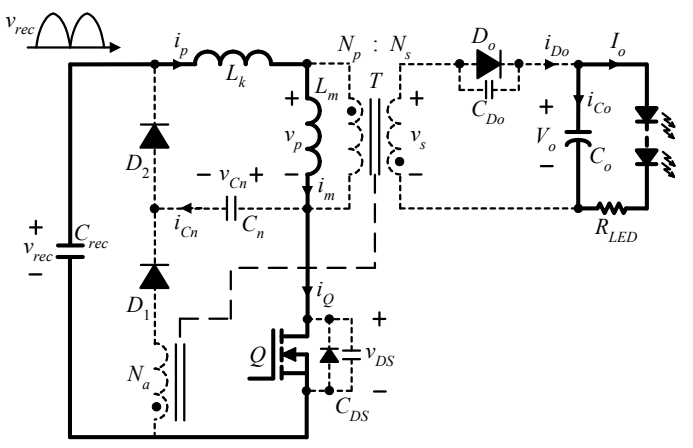

(b) Mode 2

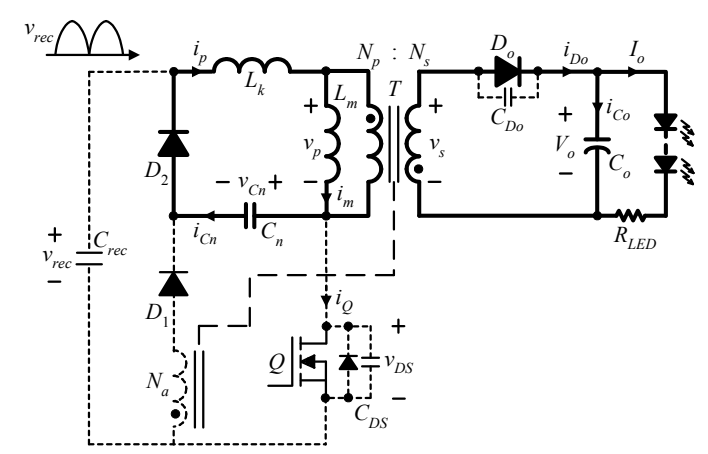

(c) Mode 3

snubber capacitor $C_{n}$ is discharged and is regenerated to the voltage source $v_{\text {rec }}$ through the auxiliary winding $N_{a}$. Fig. 4 shows another equivalent circuit of the primary $C_{n}-Q-N_{a}-D_{1}$ loop from Fig. 3(a), which is an undamped series-resonant circuit.

The snubber capacitor voltage $v_{C n}$ and resonant current $i_{r 1}$ are then given as follows:

$$
\begin{aligned}
& v_{C n}=n_{a} v_{r e c}-\left(n_{a} v_{r e c}-V_{C n, \max }\right) \cos \omega_{r 1}\left(t-t_{0}\right) \\
& i_{r 1}=i_{C n}=Z_{r 1}^{-1}\left(n_{a} v_{r e c}-V_{C n, \max }\right) \sin \omega_{r 1}\left(t-t_{0}\right)
\end{aligned}
$$

where $V_{C n \text {, max }}$ is the maximum snubber capacitor voltage, and $\omega_{r 1}=1 /\left(n_{a} \sqrt{L_{k} C_{n}}\right)$ and $Z_{r 1}=n_{a} \sqrt{L_{k} / C_{n}}$ are the resonant angular frequency and the characteristic impedance, respectively.

From (1) and (2), this mode ends at time $t=t_{1}=t_{0}+\pi / \omega_{r 1}$ when the resonant current $i_{r 1}$ or snubber capacitor current $i_{C n}$ becomes zero and the snubber diode $D_{1}$ is turned off.

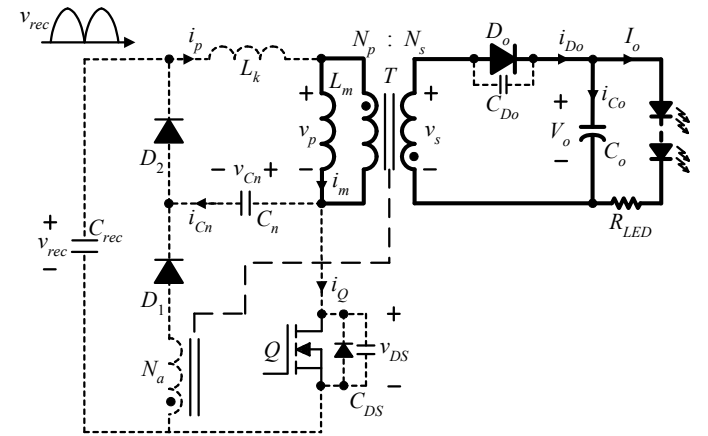

(d) Mode 4

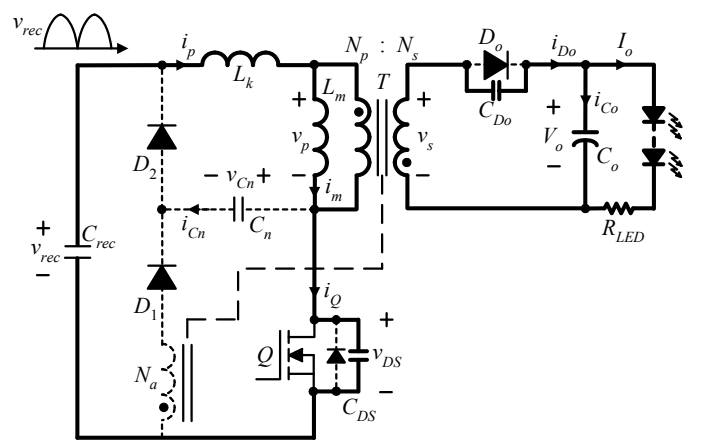

(e) Mode 5

Fig. 3. Equivalent circuits of each mode of the proposed converter.

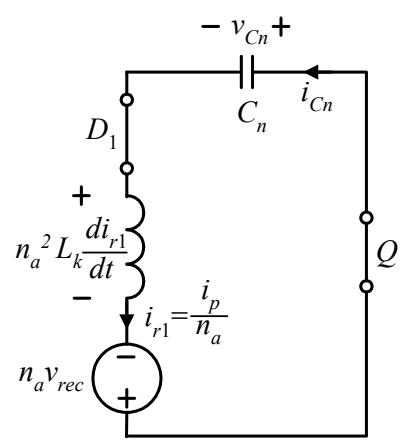

Fig. 4. Another equivalent circuit of the primary $C_{n}-Q-N_{a^{-}}$ $D_{1}$ loop of mode 1 from Fig. 3(a).

Also at the end of this mode, the snubber capacitor voltage $v_{C n}$ reaches the minimum as follows:

$$
v_{C n}\left(t_{1}\right)=V_{C n, \min }=2 n_{a} v_{r e c}-V_{C n, \max }
$$

Mode $2\left(t_{1} \sim t_{2}\right)$ : This mode starts when the snubber diode $D_{1}$ is turned off at time $t=t_{1}$. The primary series inductance $L_{m}+L_{k}$ is linearly charged by the rectified dc input voltage $v_{\text {rec }}$, and thus the primary current $i_{p}$ increases linearly as follows:

$$
i_{p}=i_{Q}=i_{m}=\frac{v_{r e c}}{\left(L_{m}+L_{k}\right)}\left(t-t_{0}\right) \approx \frac{v_{r e c}}{L_{m}}\left(t-t_{0}\right) .
$$

The snubber capacitor voltage $v_{C n}$ remains at a minimum 
constant value $v_{C n}=V_{C n \text {, min }}$ during this mode. This mode ends at time $t=t_{2}$, when the switch $Q$ is turned off and the magnetizing current $i_{m}$ increases to its maximum value $I_{m, \max }$.

Mode $3\left(t_{2} \sim t_{3}\right)$ : This mode starts at time $t=t_{2}$, when the switch $Q$ is turned off and the snubber diode $D_{2}$ is conducted. The energy in the leakage inductance $L_{k}$ is then absorbed by the snubber capacitor $C_{n}$, and the voltage stress of the switch is thus limited. Fig. 5 shows another primary equivalent circuit from Fig. 3(c), which is an undamped series-resonant circuit. Here, the voltage $v_{C n}$ and the current $i_{C n}$ of the snubber capacitor $C_{n}$ are expressed, respectively, as follows:

$$
\begin{aligned}
v_{C n}=\frac{V_{O}}{n_{s}}- & \left(\frac{V_{o}}{n_{s}}-V_{C n, \min }\right) \cos \omega_{r 3}\left(t-t_{2}\right) \\
& +Z_{r 3} i_{p}\left(t_{2}\right) \sin \omega_{r 3}\left(t-t_{2}\right) \\
i_{C n}=i_{p}= & i_{p}\left(t_{2}\right) \cos \omega_{r 3}\left(t-t_{2}\right) \\
& +Z_{r 3}^{-1}\left(\frac{V_{o}}{n_{s}}-V_{C n, \text { min }}\right) \sin \omega_{r 3}\left(t-t_{2}\right)
\end{aligned}
$$

where $i_{p}\left(t_{2}\right)$ is the primary current at time $t=t_{2}$ by (4) and is the maximum magnetizing current $I_{m, \max }$, and $\omega_{r 3}=$ $1 / \sqrt{L_{k} C_{n}}$ and $Z_{r 3}=\sqrt{L_{k} / C_{n}}$ are the resonant angular frequency and the characteristic impedance, respectively. However, if the snubber capacitor $C_{n}$ in Fig. 5 is designed so that $V_{C n \text {,min }}$ is equal to $V_{o} / n_{s}$ in (5) and (6), the following relationships are given as follows:

$$
\begin{aligned}
v_{C n} & =\frac{V_{o}}{n_{s}}+Z_{r 3} I_{m, \max } \sin \omega_{r 3}\left(t-t_{2}\right) \\
i_{C n} & =i_{p}=I_{m, \max } \cos \omega_{r 3}\left(t-t_{2}\right) .
\end{aligned}
$$

From (7) and (8), when the snubber capacitor current $i_{C n}$ drops to zero at time $t=t_{3}=t_{2}+\pi /\left(2 \omega_{r 3}\right)$, the snubber diode $\mathrm{D}_{2}$ is turned off and this mode ends. Also, at the end of this mode, the snubber capacitor voltage $v_{C n}$ reaches its maximum value as follows:

$$
\begin{aligned}
v_{C n}=V_{C n, \max } & =\frac{V_{o}}{n_{s}}+Z_{r 3} I_{m, \text { max }} \\
& =V_{C n, \min }+I_{m, \max } \sqrt{L_{k} / C_{n}} .
\end{aligned}
$$

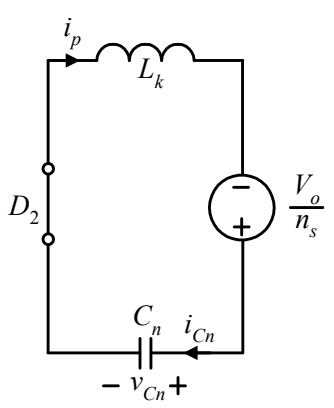

Fig. 5. Another primary equivalent circuit of mode 3 from Fig. 3(c).
Mode $4\left(t_{3} \sim t_{4}\right)$ : At time $t=t_{3}$, this mode starts when the snubber capacitor current $i_{C n}$ becomes zero and the diode $D_{2}$ turns off. Here, the energy of the magnetizing inductance $L_{m}$ linearly discharges into the output capacitance $C_{o}$ through the transformer secondary. Because both snubber diodes, $D_{1}$ and $D_{2}$, are turned off, the snubber capacitor voltage $v_{C n}$ keeps constant at a maximum $v_{C n}=V_{C n \text {,max }}$. This mode ends at time $t=t_{4}$, when the magnetizing current $i_{m}$ or the secondary current $i_{D o}$ reaches zero.

Mode $5\left(t_{4} \sim t_{5}\right)$ : At time $t=t_{4}$, the energy stored in the magnetizing inductance $L_{m}$ is discharged completely, and the secondary current $i_{D o}$ becomes zero. The magnetizing inductance $L_{m}$ and the equivalent resonant capacitance $C_{e q 5}=C_{D S}+n_{s}{ }^{2} C_{D o}$ then resonate as follows:

$$
\begin{aligned}
& i_{m}=\frac{v_{r e c}-v_{D S}\left(t_{5}\right)}{Z_{r 5}} \sin \omega_{r 5}\left(t-t_{5}\right) \\
& v_{D S}=v_{r e c}+\frac{v_{o}}{n_{s}} \cos \omega_{r 5}\left(t-t_{5}\right)
\end{aligned}
$$

where $Z_{r 5}=\sqrt{L_{m} / C_{e q 5}}$ and $\omega_{r 5}=1 / \sqrt{L_{m} C_{e q 5}}$ are the characteristic impedance and the resonant angular frequency, respectively. This mode terminates after the resonant half period, $\pi / \omega_{r 5}$. During this mode, the switch voltage $v_{D S}$ decreases, and reaches its minimum voltage, $v_{\text {rec }}-V_{o} / n_{s}$. The switch $Q$ is turned on at the end of this mode. Therefore, the turn-on switching voltage is reduced and thus the switching loss is reduced.

Subsequently, the entire process of the five modes is repeated in each switching period.

Fig. 6 shows the conceptual waveform of the main parts of the proposed converter at the ac line frequency scale for an explanation of its PFC operation. As shown in Fig. 6, the input voltage of the proposed ac-dc converter is the sinusoidal ac line voltage as follows:

$$
v_{a c}=V_{m} \sin \omega t
$$

where $V_{m}$ and $\omega$ are the amplitude and the angular frequency of the ac line input voltage, respectively. Also, as shown in Figs. 1 and 6, due to the operation of the fullbridge diode rectifier, the input voltage of the flyback converter is the full-wave rectified dc voltage $v_{\text {rec }}$ from the ac line input voltage as follows:

$$
v_{\text {rec }}=\left|v_{a c}\right|=V_{m}|\sin \omega t| \text {. }
$$

As shown in Fig. 2, the rectified dc input voltage of the flyback converter is almost constant during the switching period $T_{s}$. Then, from mode 1 and 2 and Fig. 6, the instantaneous mean value $i_{p, a v g}$ of the flyback converter input current $i_{p}$ is obtained by

$$
i_{p, a v g}=\frac{1}{T_{S}} \int_{0}^{T_{S}} i_{p} d t
$$




$$
\begin{aligned}
& =\frac{1}{T_{s}} \int_{t_{0}}^{t_{2}} \frac{v_{r e c}}{L_{m}}\left(t-t_{0}\right) d t \\
& =\frac{D^{2} T_{s}}{2 L_{m}} v_{r e c} .
\end{aligned}
$$

At this time, the ac line input current $i_{a c}$ is given by the instantaneous mean value $i_{p, a v g}$ due to the operation of the ac input filter that is generally connected to the ac input terminal of the ac-dc converter. The ac line input current $i_{a c}$ is then given by

$$
i_{a c}=\frac{D^{2} T_{s}}{2 L_{m}} V_{m} \sin \omega t
$$

The real input power $P_{\text {in }}$ is calculated as

$$
P_{\boldsymbol{i}}=\frac{1}{\pi} \int_{0}^{\pi} v_{a c} i_{a c} d \omega t=\frac{D^{2} V_{m}^{2}}{4 L_{m}} T_{s} .
$$

Then the power factor PF is given by

$$
\mathrm{PF}=\frac{P_{\dot{m}}}{V_{a c} I_{a c}}=\frac{\frac{D^{2} V_{m}^{2}}{4 L_{m}} T_{S}}{\frac{V_{m}}{\sqrt{2}} \frac{D^{2} T_{s}}{2 L_{m}} \frac{V_{m}}{\sqrt{2}}}=1
$$

where $V_{a c}$ and $I_{a c}$ are the rms values of the ac line input voltage and current, respectively.

The proposed converter can therefore obtain the unity power factor, since the full-bridge diode rectifier and the modified conventional flyback converter with the TCL snubber circuit are simply merged with only a rectified input capacitor of small value, but without an electrolytic capacitor.

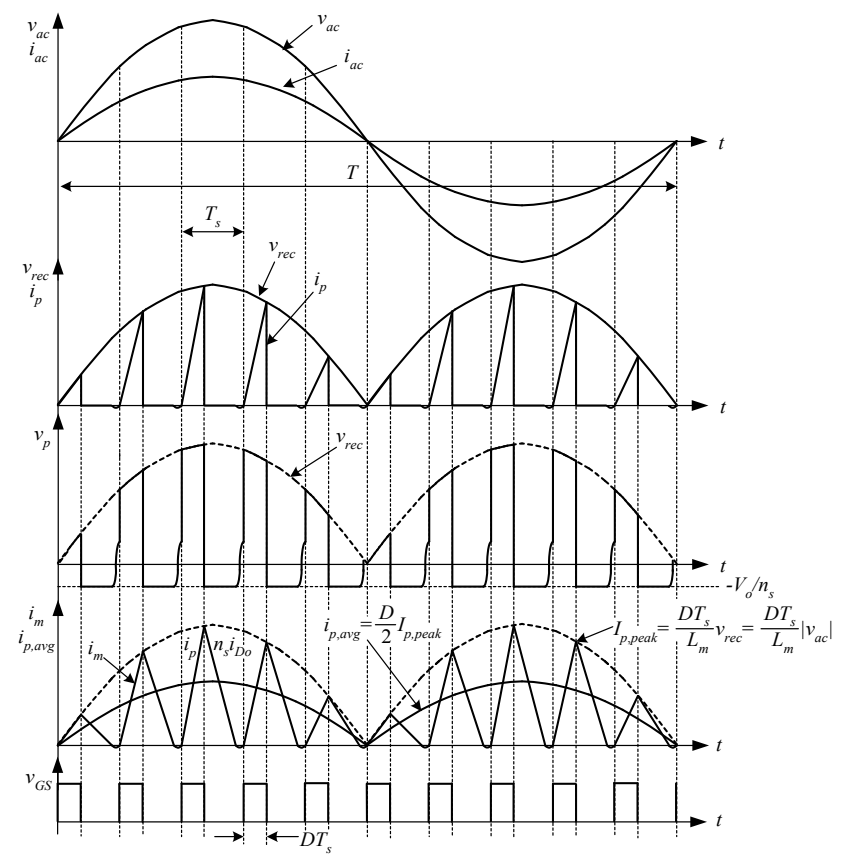

Fig. 6. Conceptual waveform of the main parts of the proposed converter at the ac line frequency scale for explanation of its PFC operation.

\section{Design Guideline}

To validate the characteristics of the proposed converter, a prototype converter is designed with the following specifications: rms ac input voltage range $V_{a c}=85 \sim 265 \mathrm{~V} /$ $60 \mathrm{~Hz}$ (rating rms ac input voltage $V_{\text {rating }}=220 \mathrm{~V}$ ), dc output voltage $V_{o}=40 \mathrm{~V}$, rating output power $P_{o}=40 \mathrm{~W}$, efficiency $\eta=91 \%$.

The proposed converter is controlled using a general voltage-mode CRM PFC control IC. Since the flyback converter of the proposed converter is the same as the conventional converter (with the exception that only the TCL snubber is applied), the design of the flyback converter follows the general design rule of the conventional flyback converter. The designed major components and parameters of the prototype used for experiments are shown in Table 1.

The design of the TCL snubber circuit is the final step in the power circuit design of the proposed converter and is performed after the other circuit parameters in Table 1 are obtained. A possible TCL snubber circuit design of the proposed ac-dc converter is as follows.

When the switch $Q$ is turned on, the diodes $D_{o}$ and $D_{2}$ are reverse-biased and turned off. The diode $D_{1}$ is turned on until the snubber capacitor voltage $v_{C n}$ drops to the reflected input voltage $n_{a} v_{r e c}$. During the switch turn-on period, the snubber capacitor voltage $v_{C n}$ can be approximated as the average snubber capacitor voltage $V_{C n}$ in mode 1 or the voltage of auxiliary winding voltage from (3) as follows:

$$
v_{C n} \approx V_{C n}=n_{a} v_{r e c}
$$

Table 1. Parameters and components of the prototype.

\begin{tabular}{ccc}
\hline \hline Parameter & Symbol & Value \\
\hline Rectified input capacitor & $C_{\text {rec }}$ & $0.47 \mu \mathrm{F}$ \\
Magnetizing inductance & $L_{m}$ & $200 \mu \mathrm{H}$ \\
Primary winding number & $N_{p}$ & $32 \mathrm{~T}$ \\
Secondary winding number & $N_{s}$ & $14 \mathrm{~T}$ \\
Output capacitor & $C_{o}$ & $2200 \mu \mathrm{F}$ \\
\hline Component & Symbol & Part number \\
\hline Switch & $Q$ & STP10NK80NZ \\
Output diode & $D_{o}$ & MBR10200 \\
Transformer core & $T$ & BEPC30 \\
Full-bridge diode & $D_{F B}$ & KBU806
\end{tabular}

However, the magnitude of the output voltage reflected in the transformer primary should be greater than the snubber capacitor voltage $v_{C n}$, so that the output diode $D_{o}$ is not reverse-biased during the switch turn-off period. Otherwise, the energy stored in the magnetizing inductance $L_{m}$ is transferred to the snubber capacitor $C_{n}$ instead of to the output. Therefore, the snubber capacitor voltage $v_{C n}$ should be satisfied by the following relation:

$$
v_{C n} \approx V_{C n}<\frac{V_{o}}{n_{s}}
$$


The auxiliary winding number $N_{a}$ is then determined by the following inequality relation:

$$
N_{a}<\frac{V_{o} \cdot N_{p}^{2}}{v_{r e c} \cdot N_{S}}
$$

Therefore, according to the given specifications and the calculated circuit parameters in Table 1, the auxiliary winding number $N_{a}$ of the prototype is determined as $N_{a}=12 \mathrm{~T}$.

In order to satisfy the relation of (19), the maximum snubber capacitor voltage $V_{C n \text {, max }}$ in (3) and (9) should satisfy the following relation:

$$
V_{C n, \mathrm{~m} \mathrm{ax}}<V_{o} \frac{N_{p}}{N_{s}}
$$

Also, the $L C$ resonance in mode 1 must also be completed during half of the $L C$ resonant period. Therefore, the possible range of the snubber capacitance $C_{n}$ is given as follows:

$$
\frac{L_{k}}{4}\left[\frac{I_{m, \mathrm{max}}}{V_{o} \frac{N_{p}}{N_{S}}\left(1-\frac{N_{a}}{N_{p}} \frac{1-D}{D}\right)}\right]^{2}<C_{n}<\frac{1}{L_{k}}\left(\frac{D T_{s} N_{p}}{\pi N_{a}}\right)^{2}
$$

where $I_{m, \max }$ is the maximum magnetizing current, $L_{k}$ is the primary leakage inductance of the transformer (which is measured in the real transformer of Table 1), and $D T_{s}$ is the nominal switch turn-on time. Therefore, the snubber capacitance $C_{n}$ is determined as $C_{n}=3.3 \mathrm{nF}$.

\section{Experimental Results}

An experimental prototype was implemented to verify the characteristics of the proposed ac-dc converter. Its specifications are shown in Section 3. The designed major components and parameters of the prototype are presented in Table 1, and its TCL snubber circuit design is shown in Section 3.

Fig. 7 shows the experimental waveforms of the input and output parts of the proposed single-stage ac-dc converter and the conventional two-stage ac-dc converter under the same rating condition. Here, the conventional two-stage ac-dc converter is composed of the boost PFC converter and the conventional flyback dc-dc converter and has the same output capacitance as that of the proposed converter. Fig. 7(a) shows the experimental waveforms of the ac input voltage $v_{a c}$, the ac input current $i_{a c}$, and the output voltage $V_{o}$ of the proposed single-stage ac-dc converter. The ac input current is sinusoidal and in-phase with the ac input voltage, and its output voltage is also well regulated. Fig. 7(b) shows the dc input voltage $V_{d c}$ and the dc output voltage $V_{o, c o n v}$ of the flyback converter of the conventional two-stage ac-dc converter, where the dc input voltage $V_{d c}$ is the output voltage of the front-end boost PFC

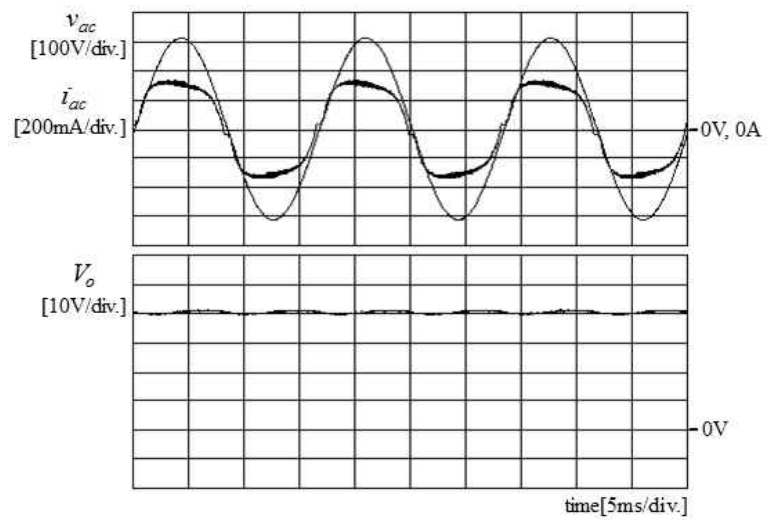

(a) ac input voltage $v_{a c}$, the ac input current $i_{a c}$, and the output voltage $V_{o}$ of the proposed converter.

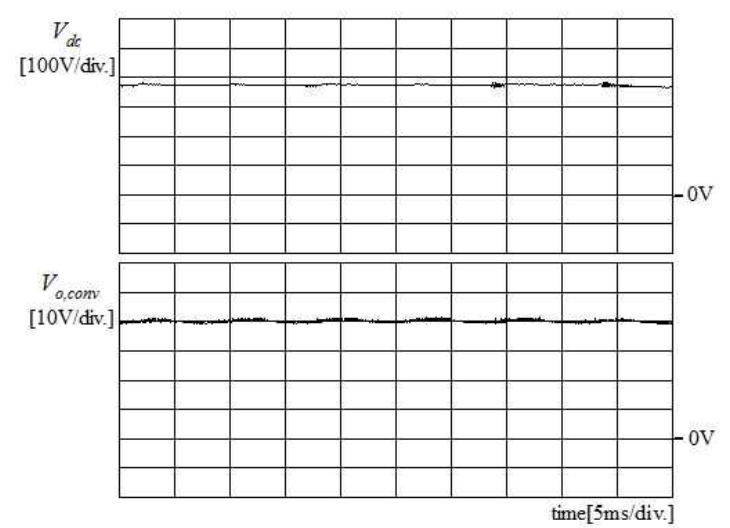

(b) dc input voltage $V_{d c}$ and the output voltage $V_{o \text {,conv }}$ of the flyback converter of the conventional converter.

Fig. 7. Experimental waveforms of the input and output parts of the proposed single-stage ac-dc converter and the conventional two-stage ac-dc converter under the rating condition.

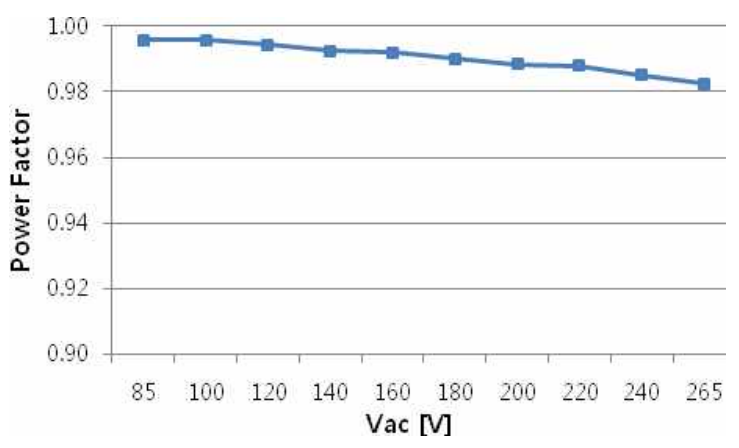

Fig. 8. Power factor variations of the proposed converter over the range of the universal ac input voltage.

converter of the conventional two-sage ac-dc converter. The output voltage characteristics of both converters only marginally differ. This is because the proposed converter also has a flyback converter structure at the dc output and its voltage regulation scheme is similar to the dc outputend flyback converter of the conventional converter. Fig. 8 
shows the power factor variations of the proposed converter over the universal ac input voltage range. The power factor of the proposed converter is high, that is, over 0.98 .

Fig. 9 shows the experimental waveforms of the main parts of the proposed converter at each frequency scale under the rating condition. Fig. 9(a) shows the experimental waveforms of the rectified dc input voltage $v_{\text {rec }}$ and the switch voltage $v_{D S}$ of the proposed converter at the ac line frequency scale. Fig. 9(b) shows the experimental waveforms of the main parts of the flyback converter of the proposed converter at the switching frequency scale. From these figures, it is confirmed that the general PFC control IC used can effectively control the proposed converter using the CRM technique, and the theoretical explanation in this paper is correct.

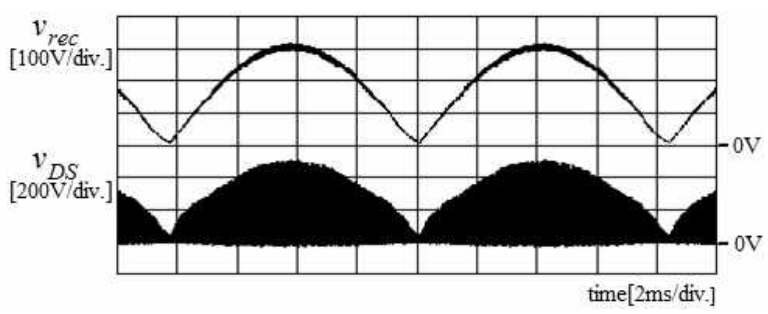

(a) Rectified dc input voltage $v_{r e c}$ and the switch voltage $v_{D S}$ at the ac line frequency scale.

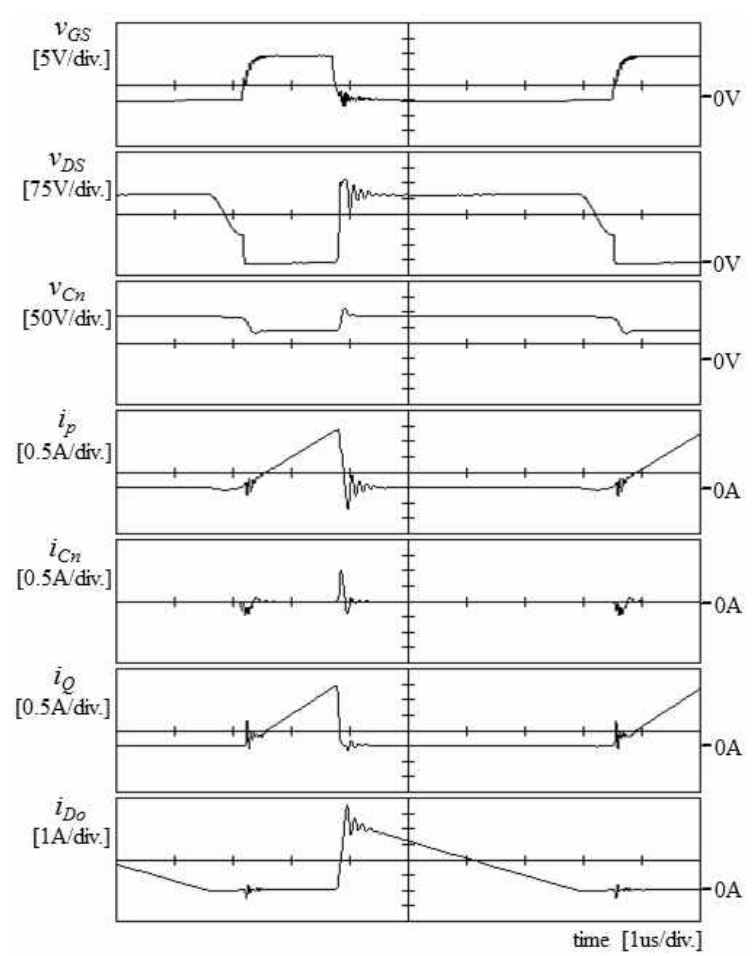

(b) Main parts of the flyback converter at the switching frequency scale.

Fig. 9. Experimental waveforms of the main parts of the proposed converter at each frequency scale.

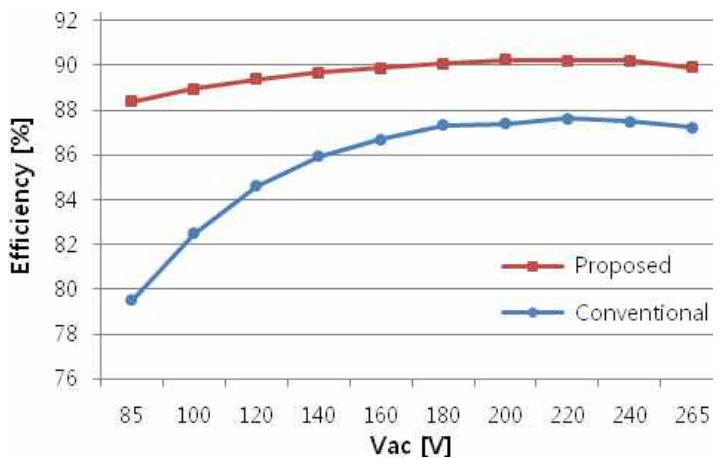

Fig. 10. Efficiency comparison of the proposed converter and the conventional single-stage ac-dc converter.

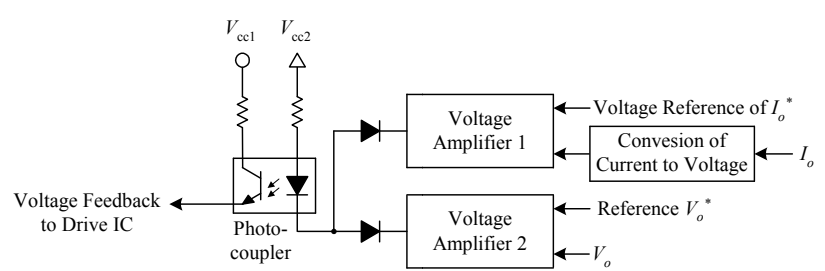

Fig. 11. Mixed current and voltage feedback conceptual diagram of each converter.

Fig. 10 shows an efficiency comparison of the proposed converter and the conventional single-stage ac-dc converter with the RCD snubber over the universal ac input voltage. The conventional converter is implemented in our laboratory with the same specifications of the proposed converter. The efficiency is measured using a digital power meter, Yokogawa WT500. The proposed converter achieves high efficiency because the conduction loss and the switch voltage stress of the proposed converter are reduced by using the improved single-stage converter structure without the separate PFC circuit and the TCL snubber circuit as its snubber. The measured maximum efficiency of the prototype is $90.2 \%$ under the rating condition.

In particular, the proposed single-stage converter shows a greater improvement of the power efficiency than the conventional single-stage converter in the low input voltage range. However, each single-stage converter shown in Fig. 10 controls the output current or the output voltage to be constant. Fig. 11 shows the mixed current and voltage feedback conceptual diagram of each converter.

The LED-driving ac-dc converters must be controlled by both the constant current (CC) mode and the constant voltage $(\mathrm{CV})$ mode. Because the forward voltage drop of the LED varies with the junction temperature and thus the current also significantly increases, the devices can become damaged. In each converter, during normal operation, the CC mode is dominant and the CV mode only acts as the over voltage protection for abnormal modes. This means that each single-stage converter controls its output power to be approximately constant. However, assuming that the converters are ideal for convenience of this explanation, the input power and the output power are the same. 


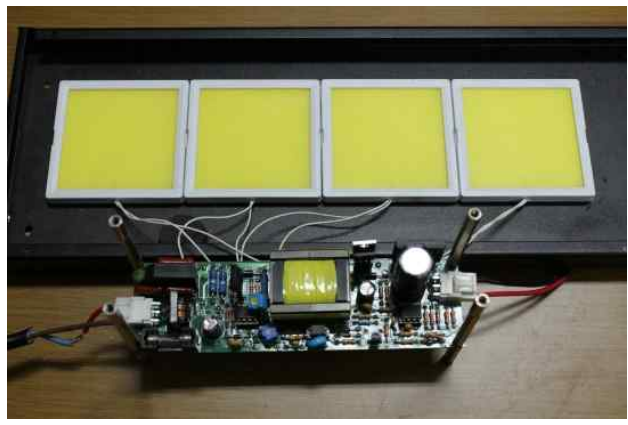

(a) Original shape of the new prototype LED modules and the prototype converter.

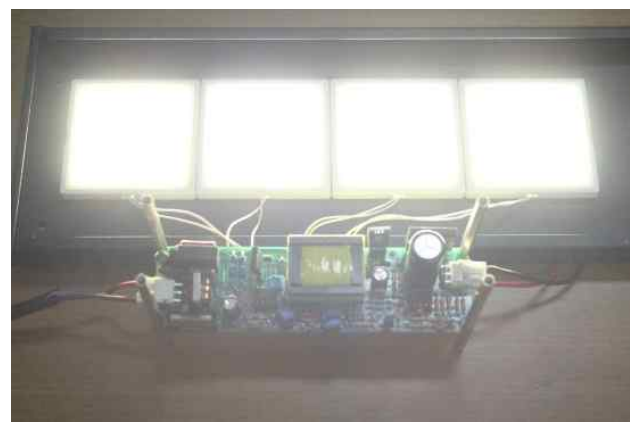

(b) New prototype LED modules and the prototype converter in operation.

Fig. 12. LEDs and the prototype converter used in the experiment.

Therefore, if the ac input voltage of the single-stage converter is lower, the input current is higher. The higher input current means that the energy due to $d i / d t$ at a switching (that must be absorbed by the snubber) is also higher. However, in the case of the conventional singlestage converter with the RCD snubber, because all the higher energy due to $d i / d t$ at a switching in the low voltage range can only be dissipated in the RCD snubber, the loss of the converter is higher especially in the low input voltage range, and thus the power efficiency of the converter is more deteriorated than in the high input voltage range. However, in the case of the proposed singlestage converter with the TCL snubber, because all the energy due to $d i / d t$ at a switching is regenerated through the TCL snubber independent of the input voltage range, the power efficiency is high even in the low input voltage and is even over the entire input voltage range as high power efficiency.

Fig. 12 shows photos of the LEDs and the prototype converter used in the experiment. The LEDs in Fig. 12 are new LED modules that are developed as a prototype for the LED lighting from an electronics company, and they are four 10-W class LED modules connected in parallel. Fig. 12(a) shows the original shape of the LED modules and the prototype converter when they do not operate, and Fig. 12(b) shows them while they are operating.

\section{Conclusion}

An improved single-stage ac-dc LED-drive flyback converter using a TCL snubber was proposed in this paper. The proposed converter simply combines the full-bridge diode rectifier and the modified conventional flyback converter with only the TCL snubber circuit without the electrolytic capacitor and boost inductor. The TCL snubber circuit comprises only two diodes, a capacitor, and a transformer-coupled auxiliary winding. Therefore, the implementation of the proposed converter is easy and costeffective. The TCL snubber limits the maximum voltage of the switch and regenerates the energy stored in the primary leakage inductance of the transformer. Also, the proposed converter turns on its switch when the switch voltage is at a minimum using a formed resonant circuit. Thus, the proposed converter achieves high efficiency. The proposed converter performs both the PFC and the output power regulation using only one general PFC control IC as its controller, simultaneously. However, the proposed converter achieves a high power factor without any separate PFC circuit. In this paper, analysis and a design guideline of the proposed converter and experimental results for the proposed converter have been presented. It is verified that the proposed converter has good performance as a single-stage LED-driving ac-dc power converter through experimental results for a $40-\mathrm{W}$ prototype.

\section{Acknowledgements}

This work was supported by the Soonchunhyang University Research Fund.

\section{References}

[1] Daniel A. Steigerwald, Jerome C. Bhat, Dave Collins, Robert M. Fletcher, Mari Ochiai Holcomb, Michael J. Ludowise, Member, IEEE, Paul S. Martin, and Serge L. Rudaz, "Illumination With Solid State Lighting Technology," IEEE Journal of Selected Topics in Quantum Electronics, vol. 8, no. 2, pp. 310-320, Mar. 2002.

[2] Jeff Y. Tsao, "Solid-State Lighting: Lamps, Chips, Materials for Tomorrow," IEEE Circuits Devices Mag., vol. 20, no. 3, pp. 28-37, May/June 2004.

[3] Michael S. Shur and Artūras Žukauskas, "Solid-State Lighting: Toward Superior Illumination," Proceedings of the IEEE, vol. 93, no. 10, pp. 1691-1703, Oct. 2005.

[4] Mary H. Crawford, "LEDs for Solid-state Lighting: Performance and Recent Advances," IEEE J. Sel. Topics in Quantum Electron., vol. 15, no. 4, pp. 10281040, July/Aug. 2009. 
[5] Ansgar Laubsch, Matthias Sabathil, Johannes Baur, Matthias Peter and Berthold Hhn, "High-Power and High-Efficiency InGaN-Based Light Emitters," IEEE Trans. Electron Devices, vol. 57, no. 1, pp. 79-87, Jan. 2010.

[6] Diego González Lamar, Javier Sebastián Zúñiga, Alberto Rodríguez Alonso, Miguel Rodríguez González, and Marta María Hernando Álvarez, "A Very Simple Control Strategy for Power Factor Correctors Driving High-Brightness LEDs," IEEE Trans. Power Electronics, vol. 24, no. 8, pp. 20322042, Aug. 2009.

[7] April (Yang) Zhao and Wai Tung Ng, "An energy conservation based high-efficiency dimmable multichannel LED driver ," Energy Conversion Congress and Exposition (ECCE) 2011, pp. 2576-2580, Sep. 2011.

[8] Hongbo Ma, Jih-Sheng Lai, Quanyuan Feng, Wensong Yu, Cong Zheng and Zheng Zhao, "A Novel Valley-Fill SEPIC-Derived Power Supply Without Electrolytic Capacitor for LED Lighting Application,' IEEE Trans. Power Electronics, vol. 24, no. 8, pp. 2032-2042, Aug. 2009.

[9] Rudolph R. Verderber, Oliver C. Morse and William R. Alling, "Harmonics from Compact Fluorescent Lamps," IEEE Trans. Industry Applications, vol. 29, no. 3, pp. 670-674, May 1993.

[10] Wu Chen, Member and S. Y. Ron Hui, "Elimination of an Electrolytic Capacitor in AC/DC Light-Emitting Diode (LED) Driver With High Input Power Factor and Constant Output Current," IEEE Trans. Power Electronics, vol. 27, no. 3, pp. 1598-1607, Mar. 2012.

[11] Jianwen Shao, "Single Stage Offline LED Driver," Applied Power Electronics Conference and Exposition (APEC) 2009, pp. 582-586, Feb. 2009.

[12] David Gacio, J. Marcos Alonso, Antonio J. Calleja, Jorge García and Manuel Rico-Secades, "A UniversalInput Single-Stage High-Power-Factor Power Supply for HB-LEDs Based on Integrated Buck-Flyback Converter," IEEE Trans. Industrial Electronics, vol. 58, no. 2, pp. 589-599, Feb. 2011.

[13] Yan-Cun Li and Chern-Lin Chen, "A Novel SingleStage High-Power-Factor AC-to-DC LED Driving Circuit With Leakage Inductance Energy Recycling," IEEE Trans. Industrial Electronics, vol. 59, no. 2, pp. 793-802, Feb. 2012.

[14] Yan-Cun Li and Chern-Lin Chen, "A Novel SingleStage High-Power-Factor AC-to-DC LED Driving Circuit With Leakage Inductance Energy Recycling," IEEE Trans. Industrial Electronics, vol. 59, no. 2, pp. 793-802, Feb. 2012.

[15] Diego G. Lamar, Manuel Arias, Alberto Rodríguez, Arturo Fernández, Marta M. Hernando and Javier Sebastián, "Design-Oriented Analysis and Performance Evaluation of a Low-Cost High-Brightness LED Driver Based on Flyback Power Factor
Corrector," IEEE Trans. Industrial Electronics, vol. 60, no. 7, pp. 793-802, July 2013.

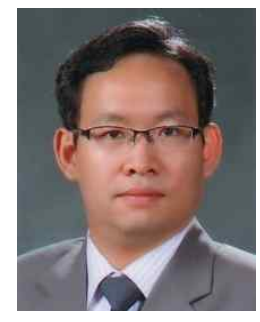

Gang-Youl Jeong He received the B.S. degree in Electrical Engineering from Yeungnam University, Gyeongsan, Korea, in 1997, and the M.S. and the Ph.D. degrees in Electronic and Electrical Engineering from POSTECH (Pohang University of Science and Technology), Pohang, Korea, in 1999 and 2002, respectively. He is currently a professor in the Department of Electronic Information Engineering, Soonchunhyang University, Asan, Korea. His research interests include DCDC power converter, DC-AC high frequency inverter, and power conversion for the renewable energy.

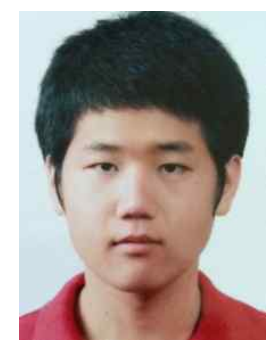

Su-Han Kwon He received the B.S. degree in Electronic Information Engineering from Soonchunhyang University, Asan, Korea, in 2013, where he is currently working toward the M.S. degree. His research interests include DC-DC power converter and DC-AC high frequency inverter. 